\title{
Interrelationship between cloud cover and sensible heat flux over land during MONTBLEX-1990
}

\author{
T Venugopal, P Seetaramayya and A R Dhakate \\ Indian Institute of Tropical Meteorology, Dr. Homi Bhabha Road, Pashan, Pune 411 008, India. \\ *e-mail: tvgopal@tropmet.res.in
}

\begin{abstract}
Micro-meteorological tower observations of MONTBLEX (Monsoon Trough Boundary Layer Experiment)-1990, combined with routine surface observations at Jodhpur in the dry convective sector of Indian summer monsoon trough are used to examine the interrelationship between total cloud cover (TCC) and surface sensible heat flux (SHF) during the summer monsoon of 1990. A significant inverse relationship between TCC and SHF is found during various Intensive Observation Periods of the experiment. This relationship holds for the various methods of estimation of SHF.
\end{abstract}

\section{Introduction}

The MONsoon Trough Boundary Layer EXperiment (MONTBLEX), conducted during 1990 in India, was the first of its kind, designed exclusively to explore the boundary layer processes along the monsoon trough (MT) region. Micrometeorological towers, each $30 \mathrm{~m}$ high, instrumented with slow and fast response sensors of temperature, wind and humidity at six (nearlylogarithmic) levels, viz., 1, 2, 4, 8, 15 and $30 \mathrm{~m}$, were installed at four locations, viz., Jodhpur, Delhi, Varanasi and Kharagpur in the vicinity of the axis of MT (figure 1). The first and the fourth locations represented the extreme convective sectors of dry and moist nature respectively, one in the northwest $\left(70^{\circ}-75^{\circ} \mathrm{E}\right)$ and the other in the southeast $\left(85^{\circ}-90^{\circ} \mathrm{E}\right)$ ends of MT (Goel and Srivastava 1990).

Rao et al (1995) observed higher (lower) magnitudes of turbulent sensible heat fluxes in weak (active) phase of monsoon at the two end sectors of MT during MONTBLEX. They also observed higher (lower) magnitudes of these fluxes in dry (moist) convective sector. However, these fluxes when day-time averaged, were found to bear no significant relationship with evening cloud cover.
Such negative relationship between sensible heat fluxes (SHF) and total cloud cover (TCC) appears to be contradictory to the findings already available in literature. For example, Dyer and Garratt (1978) showed SHF of higher magnitude under clear sky conditions, and Randall (1994) mentioned diminishing SHF under cloud shadows. In fact, a further look at the study of Rao et al (1995) (hereafter R95) itself indicates that during the weak phase with less TCC and conversely during the active phase with larger TCC, the SHF could respond inversely to TCC. The discrepancy in R95 thus appears to arise from their methodology of comparing day-time averaged (between 0800 and 1700 IST on each day) SHF with TCC of a particular instant outside the averaging time domain like the evening hour at 1730 IST.

The purpose of this paper is thus to reexamine the possibility of a qualitative interrelationship between SHF and TCC during MONTBLEX1990 over Jodhpur in the dry convective sector of MT.

The following section deals with the data used, and the methods for estimation of surface SHF. This is followed by a summary.

Keywords. IOP; TCC; eddy; bulk; profile; SHF. 


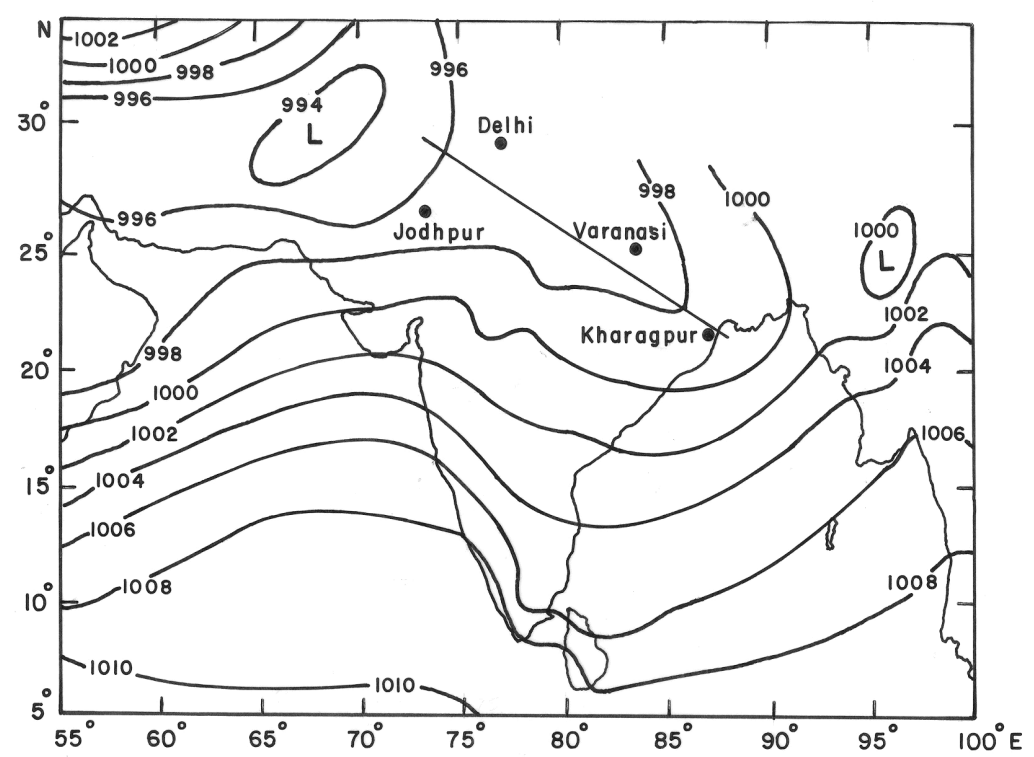

Figure 1. Mean surface pressure of July over Indian subcontinent and locations of MONTBLEX-1990 towers in the vicinity of axis of monsoon trough (thick line).

\section{Data and methods}

The data at Jodhpur $\left(26.3^{\circ} \mathrm{N}, 73^{\circ} \mathrm{E}: 224 \mathrm{~m}\right.$ amsl $)$ are of two parts, viz.,

- surface layer (SL) observations during MONTBLEX-1990 and

- routine surface observations of India Meteorological Dept. (IMD).

The details of the micro-meteorological tower instrumentation and data sampling during MONTBLEX-1990 may be found in Rudrakumar et al $(1991 \mathrm{a}, \mathrm{b})$. The reason for selecting Jodhpur for the study is due to the availability of continuous and extensive SL observations at that location. In all, 14 Intensive Observation Periods (IOP) were defined corresponding to specific synoptic situations during 1st June to 8th September (Srivastav 1995). The interval of observations was 3 hours during a normal period of the experiment and hourly during IOP. In this study, the periods chosen are the following combinations of certain IOP:

- Period I, consisting IOP 6 (26th July-1st August) and IOP 7 (3rd-8th August), and

- Period II, consisting IOP 8 (14th-18th August), IOP 9 (18th-20th August) and IOP 10 (20th25th August).

The prevailing weather conditions during these periods are described in table 1 .

The overall SL data of good quality (i.e., free from spikes) at Jodhpur comprise of:
- fast response data of wind and temperature, observed at $4 \mathrm{~m}$ level, during period I and

- slow response data of wind and temperature, observed at 1 and $15 \mathrm{~m}$ levels during period II.

The routine surface observations at Jodhpur during both the periods comprise of TCC at 0830 and 1730 IST along with daily rainfall, as reported in Indian Daily Weather Reports (IDWR) of IMD. For convenience, we treat the hours 0830 IST and 1730 IST as morning and evening respectively.

These SL data are used for the estimation of SHF by three well-known methods, viz., the eddy correlation, the bulk aerodynamic and the profile methods (Panofsky and Dutton 1983).

Denoting the eddy SHF by SHFE, it is given by

$$
\mathrm{SHFE}=\rho C_{p} \overline{w^{\prime} T^{\prime}},
$$

where $w^{\prime}$ and $T^{\prime}$ are the fluctuations of vertical wind velocity component and potential temperature respectively, $\rho$ is surface air density and $C_{p}$ is specific heat at constant pressure $\left(=1004 \mathrm{~J} \mathrm{~kg}^{-1} \mathrm{k}^{-1}\right)$.

Denoting the bulk SHF by SHFB, it is given by

$$
\mathrm{SHFB}=\rho C_{p} C_{H}|V|_{2} \Delta \theta_{1,2},
$$

where $C_{H}$ is the heat exchange coefficient, $|V|_{2}$ is the mean wind at level 2 and $\Delta \theta$ is the potential temperature difference between levels 1 and 2 .

Denoting the profile SHF by SHFP, it is given by

$$
\mathrm{SHFP}=-\rho C_{p} u_{*} \theta_{*},
$$


Table 1. Prevailing weather over India during some IOP of MONTBLEX-1990 (IDWR 1990, Srivastav 1995).

\begin{tabular}{|c|c|c|c|}
\hline \multirow[b]{2}{*}{ Period } & \multirow[b]{2}{*}{ IOP } & \multicolumn{2}{|c|}{ Weather situation } \\
\hline & & Expected & Actual \\
\hline \multirow[t]{2}{*}{ I } & $\begin{array}{l}\text { IOP 6: } \\
\text { 26th July-1st August } 1990\end{array}$ & $\begin{array}{l}\text { MT variations and possibility of } \\
\text { break monsoon }\end{array}$ & $\begin{array}{l}\text { Heavy spells of rain in the eastern } \\
\text { sector of MT; but the western sec- } \\
\text { tor remained dry. }\end{array}$ \\
\hline & $\begin{array}{l}\text { IOP 7: } \\
\text { 3rd-8th August } 1990\end{array}$ & $\begin{array}{l}\text { Passage of well-marked low over } \\
\text { south-west Rajasthan }\end{array}$ & $\begin{array}{l}\text { Heavy spells of rain in the western } \\
\text { sector of MT; but the eastern sector } \\
\text { remained less moist. }\end{array}$ \\
\hline \multirow[t]{3}{*}{ II } & $\begin{array}{l}\text { IOP 8: } \\
\text { 14th-18th August } 1990\end{array}$ & $\begin{array}{l}\text { Formation of depression in Bay of } \\
\text { Bengal and its passage across cen- } \\
\text { tral parts of India }\end{array}$ & $\begin{array}{l}\text { Depression moved towards central } \\
\text { sector of MT; the western sector } \\
\text { remained dry. }\end{array}$ \\
\hline & $\begin{array}{l}\text { IOP 9: } \\
\text { 18th-20th August } 1990\end{array}$ & $\begin{array}{l}\text { Seasonal low over south Rajasthan } \\
\text { and adjoining areas; axis passing } \\
\text { through Jodhpur }\end{array}$ & \\
\hline & $\begin{array}{l}\text { IOP 10: } \\
\text { 20th-25th August } 1990\end{array}$ & $\begin{array}{l}\text { Formation of deep depression in the } \\
\text { north Bay of Bengal }\end{array}$ & \\
\hline
\end{tabular}

where $u_{*}$ is friction velocity and $\theta_{*}$ is characteristic temperature. As temperature and wind were measured at the same levels during MONTBLEX, in Businger-Dyer forms of the universal functions, the stability parameter $(Z / L)$ is replaced in terms of the Richardson number.

In all these methods the surface air density at Jodhpur is set at $1.15 \mathrm{~kg} \mathrm{~m}^{-3}$. The heat exchange coefficient $\left(C_{H}\right)$ required for SHFB is assigned a value of $5.43 \times 10^{-3}$ which is equivalent to the drag coefficient $\left(C_{D}\right)$ as determined by Mohanty et al (1995) for the same location.

\section{Results and discussion}

\subsection{Daily rainfall distribution}

The daily rainfall received at Jodhpur during the peak summer monsoon months of July and August 1990 is shown in figure 2. As can be seen, there were four pockets of descending rain intensity $(22$, $5.5,3$ and $0.5 \mathrm{~cm}$ ) at this location when the monsoon was advancing over the country as a whole. From IDWR, it is observed that the rainfall was due to localized weather disturbances. According to the reports of Rudrakumar et al (1991a, b), there was rainfall on 5th August also (the exact quantity not being known). The selected periods (period I and II) received moderately heavy rainfall on some days. Hence the usual dry land surface at Jodhpur may be expected to have undergone rapid changes from dry to wet or wet to dry states.

\subsection{Variation of SHFE vs. TCC}

In R95, the SHF during the period 26th July-10th August 1990 were determined by eddy correlation

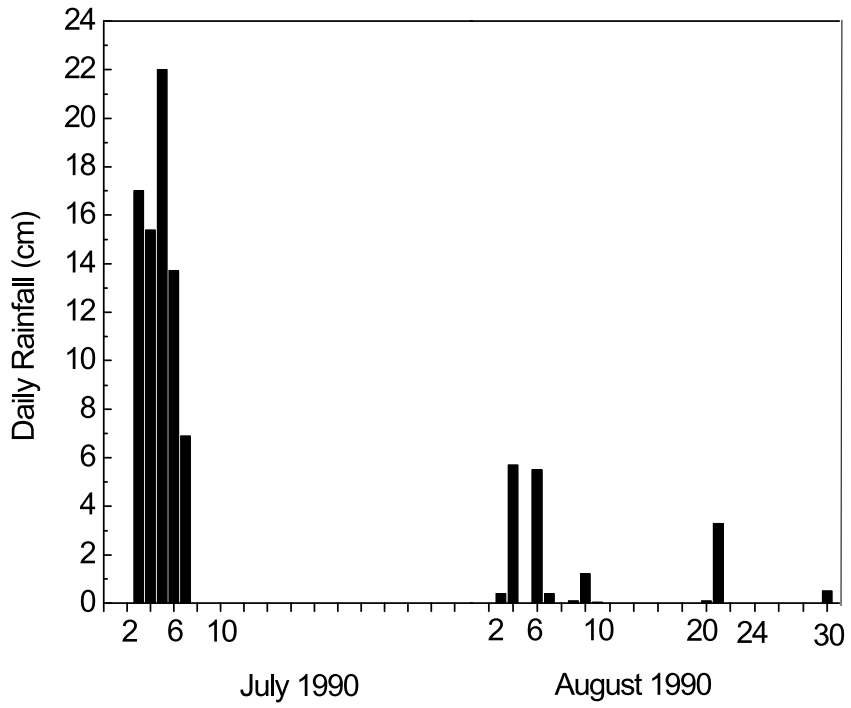

Figure 2. Daily rainfall distribution at Jodhpur during July and August 1990.

method and were termed 'turbulent heat fluxes', probably due to relatively strong surface winds $\left(3-4 \mathrm{~m} \mathrm{~s}^{-1}\right)$. In order to have a comparative study with R95, the same period but as a combination of two IOP and the same eddy method are considered here as a first step.

The SHFE along with TCC in the morning and evening during period I (26th July-8th August 1990) are shown in figure 3(a) and (b) respectively. The higher TCC (6-7 octas) in the morning during the first half of the period (IOP no. 6) may be in association with the prevailing weather in the eastern sector of MT. In general, the evening TCC was lower as compared to the morning TCC. In the second half of the period (IOP no. 7) the TCC remained higher (8 octas) in the morning as well as 
(a)

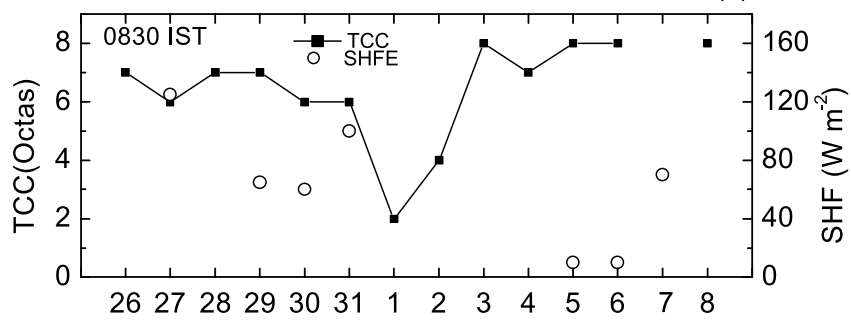

(b)

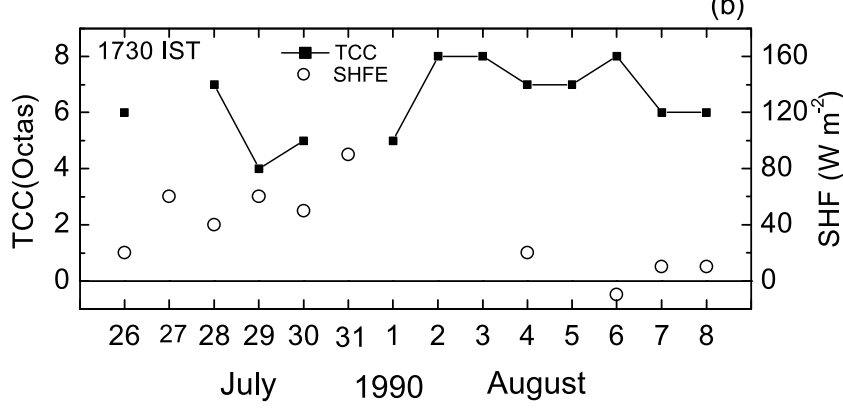

Figure 3. Variation of total cloud cover (TCC) and eddy sensible heat flux (SHFE) at Jodhpur during 26th July-8th August 1990 at (a) 0830 IST (03 UTC) and (b) 1730 IST (12 UTC).

evening in association with the localised weather disturbances (cf. table 1). The transit between these two IOPs is reflected in the abrupt fall and rise of TCC on 1st and 2nd August as a prior indication of the local weather disturbance.

For rainfall of high intensity during 4th-6th August in the second half, the TCC was 7-8 octas, whereas for the same amount of TCC in the first half, there was no rainfall.

The SHFE were all positive (indicating unstable SL) during morning and evening (except on 6th August evening), as can be expected over Jodhpur due to its geographic location. The fluxes were of the order of $40-60 \mathrm{Wm}^{-2}$ in the first half of the period; there were, however, two extremes of $100-130 \mathrm{Wm}^{-2}$. The fluxes in the evening were lower than in the morning. In the second half, the fluxes were lower $\left(\sim 20 \mathrm{Wm}^{-2}\right)$.

A distinguishable feature is the appearance of an inverse relationship between TCC and SHF, i.e., the higher the TCC, the lower the SHF and vice versa. The interrelationship is, however, qualitative. It is difficult at this stage to assign a fixed amount of SHF to a fixed TCC, as for example, when SHF of $60 \mathrm{Wm}^{-2}$ corresponded to 7 octas on one occasion, only $10 \mathrm{Wm}^{-2}$ corresponded to the same amount of TCC on another occasion in response to the prevailing weather situation.

\subsection{Recovery of unknown TCC from $R i$}

During period II (14th-25th August 1990) although the mean wind and temperature at 1 (a)
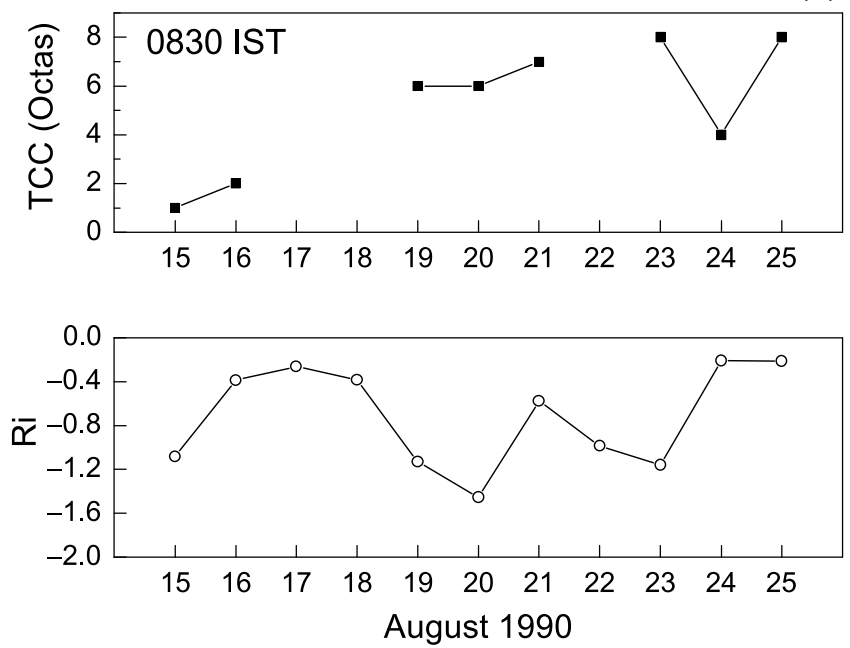

(b)
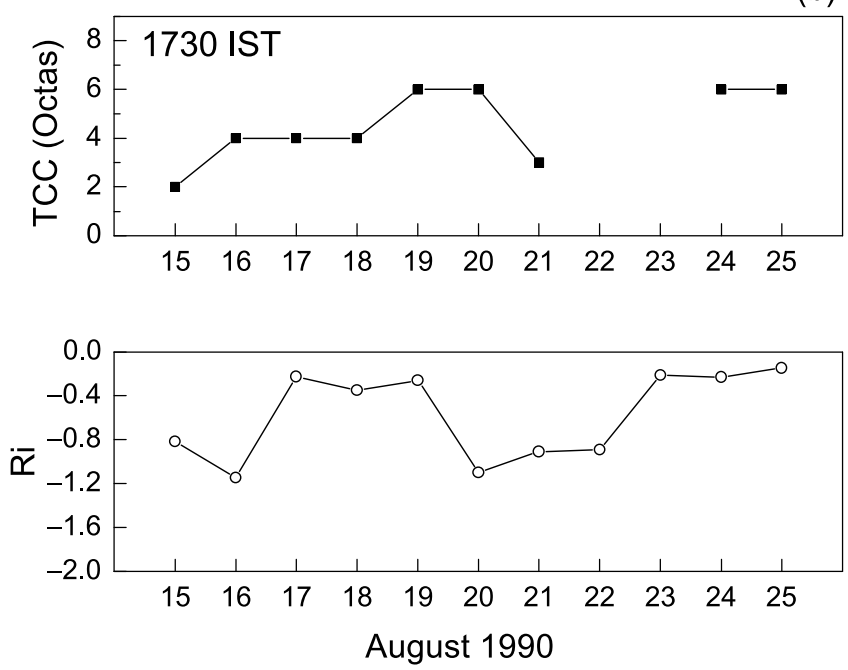

Figure 4. Variation of total cloud cover (TCC) (upper) and Richardson Number (Ri) (lower) at Jodhpur during 15th-25th August 1990 at (a) 0830 IST (03 UTC) and (b) 1730 IST (12 UTC).

and $15 \mathrm{~m}$ levels were available for all days, there were unreported TCC at times. The unknown TCC were recovered by comparing all the available TCC with Richardson number (Ri). The TCC along with $R i$ corresponding to morning and evening are shown in figure 4(a) and (b) respectively. $R i$, in general varied between -0.2 (weakly unstable SL) and -1.5 (strongly unstable SL). The TCC variation in the morning and evening, in general corresponds to two regions of $R i$, viz., $R i>-0.5$ (i.e., more towards weakly unstable SL) and $R i<-0.5$ (i.e., more towards strongly unstable SL). While in the morning, lower TCC $(\leq 4$ octas) corresponds to $R i>-0.5$, and higher TCC (6-8 octas) to $R i<-0.5$, the evening TCC behaved the opposite, i.e., lower TCC (2-4 octas) to $R i<-0.5$ and higher TCC ( $\geq 4$ octas) to $R i>-0.5$. Thus the unknown TCC in the morning on 3 days, 17th, 
18th and 22nd August can be assigned values of 1 , 2 and 7 octas respectively, corresponding to $R i$ values of $-0.26,-0.38$ and -0.98 on these days. Similarly, the unknown TCC in the evening on 22nd and 23rd August can be assigned values of 3 and 6 octas respectively, corresponding to $R i$ values of -0.89 and -0.21 on these days. From a simple linear interpolation among TCC without consideration of $R i$ would have led to TCC values of $3,5,7$ in the morning and 3,5 in the evening on the days for which TCC were unknown.

\subsection{Variation of SHFB and SHFP vs. TCC}

The TCC together with SHFB and SHFP at Jodhpur for period II (14th-25th August) are shown in figure 5(a) and (b) for morning and evening respectively. The TCC variation shows clear sky conditions during the evenings of 21st and 22nd August corresponding to no rain situation. In general, the morning TCC remained high during 19th-23rd August. The SHFB values remained in the order of $30 \mathrm{Wm}^{-2}$ in both morning and evening, while the SHFP had a higher range of $160-300 \mathrm{Wm}^{-2}$. The mean winds at $1 \mathrm{~m}$ (not shown in figures) were only of the order of $1-1.5 \mathrm{~ms}^{-1}$. The wind speed difference between 1 and $15 \mathrm{~m}$ was as low as $0.5-0.7 \mathrm{~ms}^{-1}$ on 16th and 19th August in the morning and on 15th August in the evening but it was as high as $3.0 \mathrm{~ms}^{-1}$ on 24th August in the evening. The large SHFP are thus due to either small wind shears or strong thermal gradients. Mohanty et al (1992) had observed the profile estimates to be

(a) 0830 IST

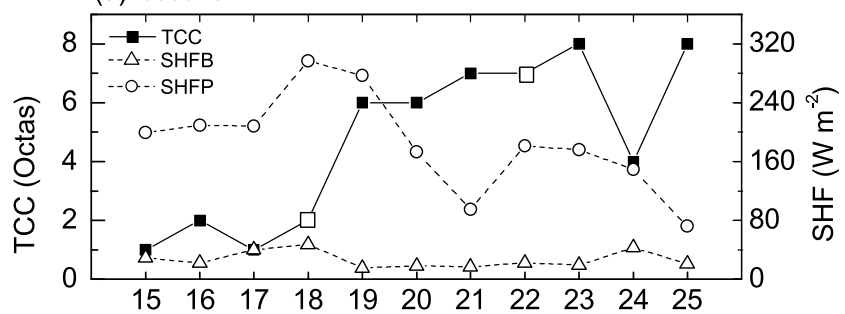

(b) 1730 IST

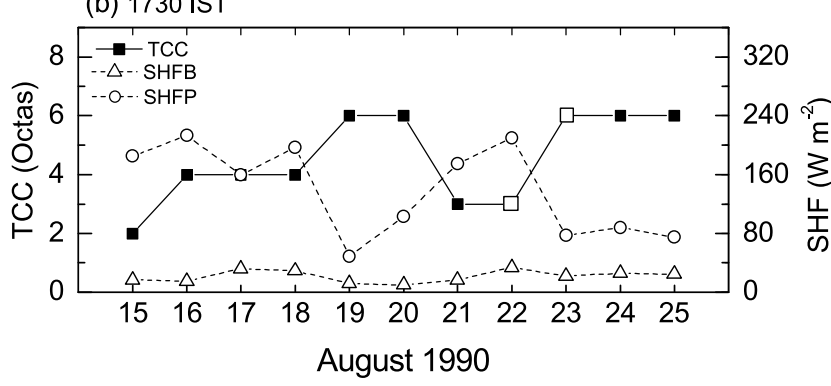

Figure 5. Variation of total cloud cover (TCC), bulk (SHFB) and profile (SHFP) sensible heat fluxes at Jodhpur during 15th-25th August 1990 at (a) 0830 IST (03 UTC) and (b) 1730 IST (12 UTC). approximately five (ten) times larger than the bulk estimates at Jodhpur in the pre-sunrise hour (sunset hour) when $C_{H}$ was $1.4 \times 10^{-3}$ during 8 th- 12 th July 1990, the days free from rain (cf. figure 1). The value of $5.43 \times 10^{-3}$ assigned for $C_{H}$ at Jodhpur thus appears to be valid for nearly neutral conditions whereas $C_{H}$ can even be one order higher in unstable conditions.

Thus, SHFB as well as SHFP, in this case, also show an inverse interrelationship with TCC during both morning and evening.

\section{Summary}

We have used simultaneous observations of total cloud cover (TCC) and surface sensible heat flux (SHF) at 0830 IST (03 UTC) and 1730 IST (12 UTC) at Jodhpur in the dry convective sector of the Indian summer monsoon trough during MONTBLEX-1990, to discuss the following interrelationship between TCC and SHF:

- There exists an inverse relationship between TCC and surface SHF (i.e., the higher the TCC, the lower the SHF and vice versa) both in the morning and evening hours.

- Their inverse relationship exists irrespective of the methods of estimation of SHF (i.e., eddy/bulk/profile).

- Comparing day-time averaged SHF with evening TCC, Rao et al (1995) arrived at a conclusion that between the two parameters there exists no correlation. However, reexamining it (as done here) by considering simultaneous observations of SHF and TCC, both in the morning and evening, the two parameters are found to be inter (inversely) related during MONTBLEX-1990.

\section{Acknowledgements}

The authors are thankful to Dr. G B Pant, Director, IITM for providing facilities; to the IMD for IDWR; to DST(GoI) for MONTBLEX data; and to Dr. Kusuma G Rao for useful discussions.

\section{References}

Dyer A J and Garratt J R 1978 The variation of eddy fluxes with height and fetch in an unstable atmosphere; J. Meteor. Soc. Japan 56 19-33.

Goel M and Srivastava H N 1990 Monsoon Trough Boundary Layer Experiment (MONTBLEX); Bull. Am. Meteor. Soc. 71 1594-1600.

Mohanty U C, Venugopal T, Parihar P S, and Goel M 1992 A Comparitive Study on Estimation of Surface Fluxes at Jodhpur Using MONTBLEX-90 Data; CAS, IIT Delhi and DST New Delhi, October. 
Mohanty U C, Parihar P S, Venugopal T and Parashuram 1995 Estimation of drag coefficient over the western desert sector of the Indian summer monsoon trough; Proc. Indian Acad. Sci. (Earth Planet. Sci.) 104(2) 273-287.

Panofsky H A and Dutton J A 1983 'Atmospheric Turbulence'; John Wiley \& Sons, NY.

Randall D A 1994 'The role of cloud in the general circulation of the atmosphere' in Parameterisation of subgrid scale physical processes; ECMWF seminar proceedings, 5-9 September.

Rao Kusuma G, Sethuraman, Prabhu A and Narasimha R 1995 Turbulent heat flux variation over the monsoon trough region during MONTBLEX-90; Atmos. Environ. 29 (16), 2113-2129.

Rudrakumar S, Srinivasan H P, Sri Krishna R, Ameenulla S and Prabhu A 1991a Available tower data from MONTBLEX-90; Tech. Report, 91 M D 1, Jan., Centre Atmos. \& Ocean. Sci., IISc, Bangalore.

Rudrakumar S, Srinivasan H P, Satyadev H N, Ameenulla S and Prabhu A 1991b Surface layer data from MONTBLEX-90; Tech. Report, 91 M D 2, Sept., Centre Atmos. \& Ocean. Sci., IISc, Bangalore.

Srivastav S K 1995 Synoptic meteorological observations and weather conditions during MONTBLEX-90; Proc. Indian Acad. Sci. (Earth Planet Sci.) 104 189-220.

MS received 6 September 2004; accepted 15 April 2005 